\title{
SOX4 inhibits GBM cell growth and induces G0/G1 cell cycle arrest through Akt-p53 axis
}

\author{
Jing Zhang ${ }^{1,2}$, Huawei Jiang ${ }^{1,2}$, Jiaofang Shao ${ }^{3}$, Ruifang Mao², Jie Liư², Yingying Ma², Xuefeng Fang ${ }^{1}$, Na Zhao²,
} Shu Zheng ${ }^{1 *}$ and Biaoyang Lin ${ }^{1,2,4^{*}}$

\begin{abstract}
Background: SOX4 is a transcription factor required for tissue development and differentiation in vertebrates. Overexpression of SOX4 has been reported in many cancers including glioblastoma multiforme (GBM), however, the underlying mechanism of actions has not been studied. In this study, we investigated the role of SOX4 in GBM.

Methods: Kaplan-Meier analysis was performed to assess the association between SOX4 expression levels and survival times in primary GBM samples. Cre/lox P system was used to generate gain or loss of SOX4 in GBM cells, and microarray analysis uncovered the regulation network of SOX4 in GBM cells.

Results: High SOX4 expression was significantly associated with good prognosis of primary GBMs. SOX4 inhibited the growth of GBM cell line LN229, A172G and U87MG, partly via the activation of p53-p21 signaling and down-regulation of phosphorylated AKT1. Gene expression profiling and subsequent gene ontology analysis showed that SOX4 influenced several key pathways including the Wnt/ beta-catenin and TGF-beta signaling pathways.

Conclusions: Our study found that SOX4 acts as a tumor suppressor in GBM cells by induce cell cycle arrest and inhibiting cell growth.
\end{abstract}

\section{Background}

The sex-determining region Y (SRY) box (SOX) gene family, characterized by the highly conserved HMG-domain responsible for sequence specific DNA binding, encodes transcription factors that are essential for embryonic development, cell fate determination, differentiation, and proliferation [1]. So far, twenty pairs of SOX genes have been identified in the human and mouse genomes [2].

SOX4 has been found to be over-expressed in adenoid cystic carcinoma (ACC), hepatocellular carcinoma, bladder tumors, acute myeloblastic leukemia, prostate cancer, endometrial cancer and glioblastoma [3-8]. SOX4 was further identified as a common transcription factors for neoplastic transformation and progression in a large-scale meta-analysis of cancer microarray data [9]. However, SOX4's mode of action in cancer is complicated as SOX4 can act either as an oncogene $[4,10,11]$ or a tumor suppressor $[4,12]$. As an oncogene, SOX4 overexpression

\footnotetext{
*Correspondence: zhengshu@zju.edu.cn; Biaoylin@gmail.com

'Cancer Institute (Key Laboratory of Cancer Prevention and Intervention, China National Ministry of Education), Second Affiliated Hospital, College of Medicine, Zhejiang University, Hangzhou, Zhejiang Province, P R China

Full list of author information is available at the end of the article
}

predicts poor outcome of colorectal cancer [13]. Its overexpression in prostate cancer correlated strongly with Gleason score [6]. Knock down of SOX4 induced apoptosis in prostate cancer cells [6] and adenoid cystic carcinoma ACC3 cells [3]. SOX4's role in bladder is perplexing: SOX4 is over expressed in bladder cancer tissues compared to normal tissues, but strong SOX4 expression was found to be correlated with increased patient survival ( $\mathrm{P}<0.05)$ of bladder cancer [4], and when introduced to bladder cancer cell line HU609, it reduced cell viability by promoting apoptosis and necrosis [4]. As a tumor suppressor, introduction of SOX4 into hepatocarcinoma Hep3B and HepG2 cells induced apoptosis via the caspase cascade with caspase-1 activation [14]. In HeLa cells, SOX4 was shown to also induce apoptosis via the caspase dependent pathway [15].

Glioblastoma multiforme is the most common and aggressive type of malignant gliomas (WHO grade IV) with an annual incidence of 2 to 3 per 100,000 population [16]. Currently, the standard therapy for gliomas consists of maximal surgical resection, followed by chemotherapy [16]. However, because of its malignant features manifested by fast growth and chemo- or radio-resistance, most 
of patients die from the recurrence with malignant gliomas within one year [17]. Others and we have showed that SOX4 is a target of TGF-beta signaling and is involved in maintaining stemness of glioma-initiating cells $[4,8,18,19]$. To further understand the molecular mechanism of SOX4 in GBM, in this study, we systematically studied the function of SOX4 in GBM cells using the Cre/ lox $P$ system to generate gain or loss of SOX4 in GBM cells. We showed that SOX4 inhibited the growth of GBM cells. A gene expression profiling analysis showed that SOX4 influenced several key pathways including the Wnt/ beta-catenin and TGF-beta signaling pathways. Finally, we showed the activation of p53-p21 signaling and downregulation of phosphorylated AKT1 by SOX4. These data provide new molecular insights into how SOX4 exerts its functions in glioma cells.

\section{Methods}

\section{Survival analysis}

Z-Scores of mRNA of SOX4 from all three platforms (U133 microarray, Agilent and RNA Seq V2 RSEM) for Glioblastoma Multiforme (TCGA, Provisional) dataset were downloaded using cBioPortal [20,21]. Univariable survival analysis was performed by the Kaplan-Meier method and log-rank test with 'survival' $R$ package version 2.37-7 [22].

\section{Cell lines and cell culture}

Human glioma cell lines LN229, T98G, U87MG, U251MG, A172, M059J and M059K were obtained from the American Type Culture Collection. All cells were maintained in Dulbecco's modified Eagle's medium (DMEM) with $10 \%$ fetal bovine serum (FBS) and $1 \%$ penicillinstreptomycin in a humidified incubator with $37^{\circ} \mathrm{C}$ and $5 \%$ $\mathrm{CO}_{2}$.

\section{Plasmid construction, retrovirus infection and transfection} The SOX4 gene from a vector containing SOX4-eYFP (a gift from Carlos S. Moreno, Emory University) was cloned by PCR and inserted into a retrovirus plasmid pBrit-HA/ Flag (Plasmid 17519, Addgene, Cambridge MA) between the two lox $P$ sites using restriction enzyme BamHI and EcoRI. A 5' primer containing a Flag tag was used and the final construct was designed to express the Flag-SOX4-HA fusion protein, forward primer (5'-cgcGGATCCgcgATG GATTACAAGGATGACGACGATAAGATGgtgcagcaaacca aca-3'), reverse primer (5'-ccggaattcGTAGGTGAAAAC CAG-3').

Retrovirus was packaged by co-transfect pBrit-FlagSOX4-HA/pBrit-Flag-HA together and pcl-Ampho plasmids into $293 \mathrm{~T}$ cells with the protocol previously described [23], SOX4 overexpression cells (named as LN229_pSFH or A172_pSFH or U87_pSFH respectively for the cell line used) and control cells (named as LN229_con or A172_con or U87_con respectively for the cell line used) were cultured by infecting the respective GBM cell lines with the virus. After 96hours, cells were selected in culture media contains $800 \mathrm{ng} / \mathrm{ml}$ puromycin (Sigma) for 3 weeks. Survival cells were harvested for functional study and analysis.

For transient transfection, SOX4-HA was cloned to the pCMV-Tag2C vector to generate the Flag-SOX4-HA plasmid. Cre recombinase cDNA from the $\mathrm{pACN}$ vector [24] (a gift from Dr. Mario Capecchi, University of Utah) was cloned into the pEGFP-N1 to construct the Cre -GFP plasmid. Flag-HA-GFP plasmid was used as the control. 48 hours after transfection, cells were harvested for further analysis and cell functional test.

\section{Cell proliferation assay}

Cell growth curves were obtained by measuring cell viability with the Cell Counting Kit-8 (CCK-8, Dojindo, Japan) according to the manufacturer's instruction. $10^{3}$ cells/well were seeded into 96-well plate on day zero and then cultured for five days. Cell viability was assessed at $6 \mathrm{~h}$ (hours), $24 \mathrm{~h}, 72 \mathrm{~h}$, and $120 \mathrm{~h}$, and normalized to the cell viability measurement at $6 \mathrm{~h}$ for each group. Each group was measured in triplicate.

\section{Cell cycle analysis}

For cell cycle analysis, $5 \times 10^{5}$ cells from each sample were trypsinized to make single cell suspension. The cells were then washed with PBS and fixed in 95\% ethanol. The cells were treated with RNAse A and stained with propidium iodide (PI) and subjected FACS analysis.

\section{Colony formation assay}

Cells were plated into 6-well plates at 400 cells/well in DMEM culture medium and further incubated for 2 weeks when colonies were sufficiently large for visualization. Colonies were then fixed in methanol and stained with $0.5 \%$ crystal violet (Sigma). The stained cells were quantified. Each group was measured in triplicate.

The soft agar assay was performed in 12-well plates containing two layers of Sea Plague Agar (Invitrogen). The bottom layer consisted of $0.8 \%$ agar in $1 \mathrm{ml}$ of DMEM with $10 \% \mathrm{FBS}$ and the top layer consisted $10^{3}$ cells of stable overexpression cells or control cells. Cells were seeded in each well and cultured for three weeks. Colonies were photographed under a microscope and counted.

\section{Reverse transcription and real-time PCR}

RNAs from cell lines were extracted using TRIZOL (Invitrogen) and $1 \mu \mathrm{g}$ of total RNAs was reverse transcribed into cDNAs using ReverTra Ace qPCR RT Kit (Toyobo, Japan). For quantitative real-time PCR, 20ng of cDNAs was used as template using the $\mathrm{SYBR}^{\oplus}$ Premix Ex $\mathrm{Taq}^{\mathrm{ma}}$ II (Taraka, Japan). GAPDH was used as control. Primers for 
target genes were listed in (Additional file 1: Table S1). Relative expression was calculated as described [25].

\section{Immunoblotting and analysis}

Cells were washed twice with PBS and lysed in RIPA buffer (25mM Tris $\mathrm{HCl}, \mathrm{pH} 7.6,150 \mathrm{mM} \mathrm{NaCl}, 1 \% \mathrm{NP}-40,1 \%$ sodium deoxycholate, $0.1 \%$ SDS, $1 \mathrm{mM}$ PMSF [P7626, Sigma] with the Protease Inhibitor Cocktail [Roche]). Nuclear and cytosolic fractions were extracted using a nuclear protein extraction kit (Beyotime, Jiangsu, China) according to the manufacturer's instructions. Protein concentration was determined using the BCA protein kit (23225, Thermo, USA). Total cell lysate $(30 \mu \mathrm{g})$ and nuclear or cytosolic fractions $(15 \mu \mathrm{g})$ were loaded on SDS-PAGE and electrophoretically transferred to polyvinylidene difluoride membrane (Milipore, Bedford, MA). The membranes were blocked with $5 \%$ milk protein in TBST $(0.6 \%$ Tween, 10 $\mathrm{mM}$ Tris pH7.6 and $150 \mathrm{mM} \mathrm{NaCl}$ in $\mathrm{H}_{2} \mathrm{O}$ ) and incubated with primary antibodies at $4{ }^{\circ} \mathrm{C}$ overnight followed by incubation with secondary antibody for $1 \mathrm{~h}$ at room temperature before exposure. Primary antibodies used were: anti-HA antibody (1:10000, ab9110, Abcam), anti-beta-catenin antibody(1:2000, ab32572, Abcam), anti-p53 antibody (1:1000, ab32389, Abcam), anti-AKT1 antibody(1:500, ab81283, Abcam), anti-AKT1p antibody(1:500, ab81283, Abcam), anti-p21 antibody(1:500, AM2385, Abzoom),anti-Ki67 antibody(1:250, ab92742, Abcam), anti-GAPDH antibody (1:2500, ab9485, Abcam), anti-Histone H3 antibody (1:2500, 2134-1,Epitomics), Anti-beta Catenin (phospho S33 + S37) antibody (1:1000, ab75777, Abcam).

\section{Expression profiling and Gene Ontology analysis}

In order to identify genes subjected to SOX4's regulation in GBM cells, total RNAs from SOX4 overexpression stable cell lines LN229_pSFH and LN229_con were used for expression profiling using the PrimeView Human Gene Expression Array (Affymetrix) using a standard Affymetrix protocol. The array data were submitted to the GEO database (GSE51301). Gene Ontology analysis was done using the DAVID program (http://david.abcc. ncifcrf.gov/) [26,27].

\section{Statistical analysis}

Statistical analysis was performed using the Student's ttest. $\mathrm{P}<0.05$ was considered to be statistically significant. The results are reported as mean \pm SD .

\section{Results}

High SOX4 expression was significantly associated with good prognosis of primary GBMs

We have previously reported that SOX4 is overexpressed in primary GBM tissues compared to normal brain tissues [8]. In this study, we analyzed the expression level of SOX4 and its association with GBM patient survival using the data from TCGA (Additional file 2: Table S2) including data from all three analytical platforms (U133 microarray, Agilent and RNA Seq V2 RSEM). We downloaded the data using cBioPortal $[20,21]$. The expression levels of the SOX4 in the downloaded data were computed and represented as the Zscores, which are the number of standard deviations away from the mean of expression in the population. 85 patients with SOX4 mRNA Z-Scores $>1$ were grouped into the high-SOX4 group, and 79 patients with ZScores $<-1$ into the low-SOX4 group. The remaining 331 patients were regarded as the median-SOX4 group. Using Kaplan-Meier survival analysis, we found that the overall survival status was significantly different between the groups with different SOX4 expression level (logrank test $\mathrm{p}$-value $=0.0104$ ). The hazard ratio of the low-SOX4 is 1.65 , and the hazard ratio of the median-SOX4 group is 1.46 , which are both significantly greater compared with the hazard ration of 1 in the high-SOX4 group ( $\mathrm{P}$ values of 0.006 and 0.0073 respectively (Figure 1), indicating that high SOX4 expression is strongly associated with the good prognosis of GBM patients.

\section{Overexpression of SOX4 reduces cell proliferation and colony formation in GBM cells}

To understand the protective mechanism of goof prognosis of high expression SOX4 for GBM patients, we decided to overexpress the SOX4 gene in GBM cell lines and to assess its impact on cell proliferation and colony formation. In order to find a suitable GBM cell lines for overexpression SOX4, we compared the SOX4 expression at mRNA levels for seven GBM cell lines LN229, T98G, U87, U251, A172, M059J and M059K by realtime PCR (Additional file 3: Figure S1). We found that GBM cell line LN229 have relative lower expression of SOX4 than others.

We started with testing the functional consequences of SOX4 overexpression using a transient expression system. We transiently transfected GBM cell line LN229 with the Flag-SOX4-HA construct and we used the empty vector pEGFP-N1 construct without the HA tag as the control. Forty-eight hours after transfection, we detected marked increase of SOX4 protein expression in LN229 cells by western blot with anti-HA antibody (Figure 2A), as shown by the band at $70 \mathrm{KDa}$ for the Flag-SOX4-HA protein $[10,28]$.

By cell proliferation assay, we found that LN229 cells with transient SOX4 overexpression grew significantly slower than cells with the control construct (Figure 2B). In addition, SOX4 overexpression cells lost the ability to form colonies (Figure 2C). FACs analysis showed an increased accumulation of SOX4 overexpression LN229 cells in the G0/G1 phase (65.3\%) compared with the cells with Flag-HA-GFP control (59.6\%), $\mathrm{p}<0.05$ (Figure 2D). 


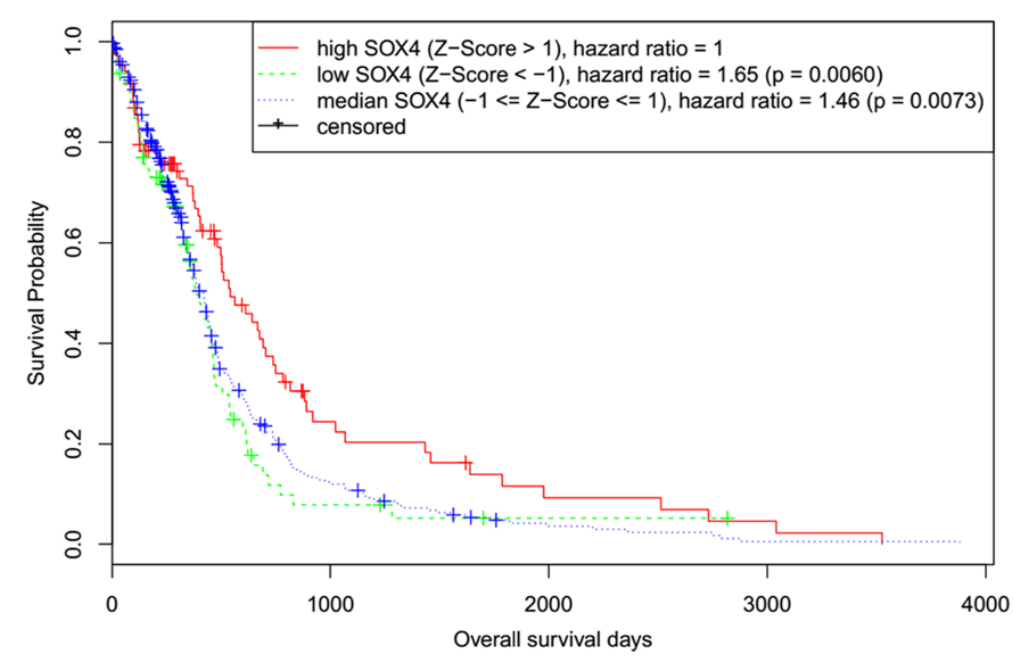

Figure 1 Kaplan-Meier analysis comparing SOX4 mRNA status with survival in primary GBM samples. Z-Scores of mRNA of SOX4 (TCGA, Provisional) were downloaded using cBioPortal. Kaplan-Meier survival analysis of SOX4 expression in primary GBM showed the overall survival status was significantly different between the groups with different SOX4 expression level. The hazard ratio of low-SOX4(Z-Score $<1$ ) or median-SOX4 $(Z$-Score $=1)$ patients was larger than high-SOX4(Z-Score $>1)$ with p-value $<-0.01$.

Encouraged by our data from the transient analysis, we decided to stably over express SOX4 in GBM cells. In order to easily remove the SOX4 in the overexpression construct as a way to study functional reversal, we decided to use a Cre/lox $\mathrm{P}$ recombination system to engineer SOX4 overexpression. GBM cell lines LN229, A172, U87MG were selected to over-express Flag-SOX4-HA by retroviral infection. After selected with $800 \mathrm{ng} / \mathrm{ml}$ puromycin for three weeks, cells were harvested and their expression of exogenous Flag-SOX4-HA were validated by real-time PCR and western blot (Figure 3A).

SOX4 overexpression cells in all of the three cell lines LN229, A172, U87MG showed reduced cell proliferation with stable SOX4 expression (Figure 3B). LN229_pSFH and A172_pSFH showed reduced colony formation capabilities compared with LN229_con and A172_con cells (Figure 3C). For U87 GBM cell lines, because SOX4 overexpression changed its morphology (Additional file 4: Figure S2), we did soft agar assay instead. After being cultured in suspended condition for three weeks, colonies of U87_con were visible by eyes while U87_pSFH could not form sphere from single cell (Figure 3D). In summary, SOX4 overexpression inhibits cell proliferation in GBM cells and also blocked the anchorageindependent growth ability of U87 GBM cells.

\section{Knock out SOX4 by Cre recombinase promotes cell proliferation in LN229 cells}

To see whether the effect of SOX4 overexpression on cell proliferation is reversible, we took advantage of the loxP system in our construct where the SOX4 gene can be removed after introducing Cre recombinase to the cells. To estimate the potential influence of Cre recombinase on cell, we did transient transfection of Cre-GFP construct into LN229 cells and no significant changes on cell proliferation or colony formation ability of LN229 cells were found (Figure 2B and C). 48 hours after transfection of Cre-GFP plasmid, exogenous SOX4 expression was reduced about 50\% in LN229_pSFH cells with Cre recombinase compared with the control cells without Cre (transfected with the pEGFP-N1 plasmid instead) (Figure 4A), and the cell proliferation increased dramatically at day 5 in LN229_pSFH cells with Cre recombinase compared to that for the control cells (Figure 4B). Flow cytometry analysis showed a decreased accumulation of cells in the G0/G1 phase (65\%) for pSFH cells transfected with Cre-GFP compared with that for pSFH cells transfected with pEGFP-N1 (75.9\%), although pSFH cells transfected with Cre still have higher number of cells at G0/G1 phase (65\%) compared with that in LN229_con cells (60.8\%) (Figure 4C). These data suggested that SOX4 suppressed GBM cell proliferation by inducing G0/G1 cell cycle arrest.

\section{Global expression profiling of SOX4 regulated genes}

To identify genes regulated by SOX4 in GBM cells, we used Affymetrix's The GeneChip ${ }^{\oplus}$ PrimeView $^{\text {тм }}$ Human Gene Expression Array to compare SOX4 overexpression LN229_pSFH and LN229_con cells. We identified 633 genes were changed more than 1.8 fold (Additional file 5: Table S3). The array data was confirmed by doing real-time PCR, and 9 of 10 randomly selected changed genes identified by array was confirmed by RT-PCR (Figure 5A).

We performed GO analysis with $633 \mathrm{SOX} 4$ regulated genes and found that they are enriched in biological 


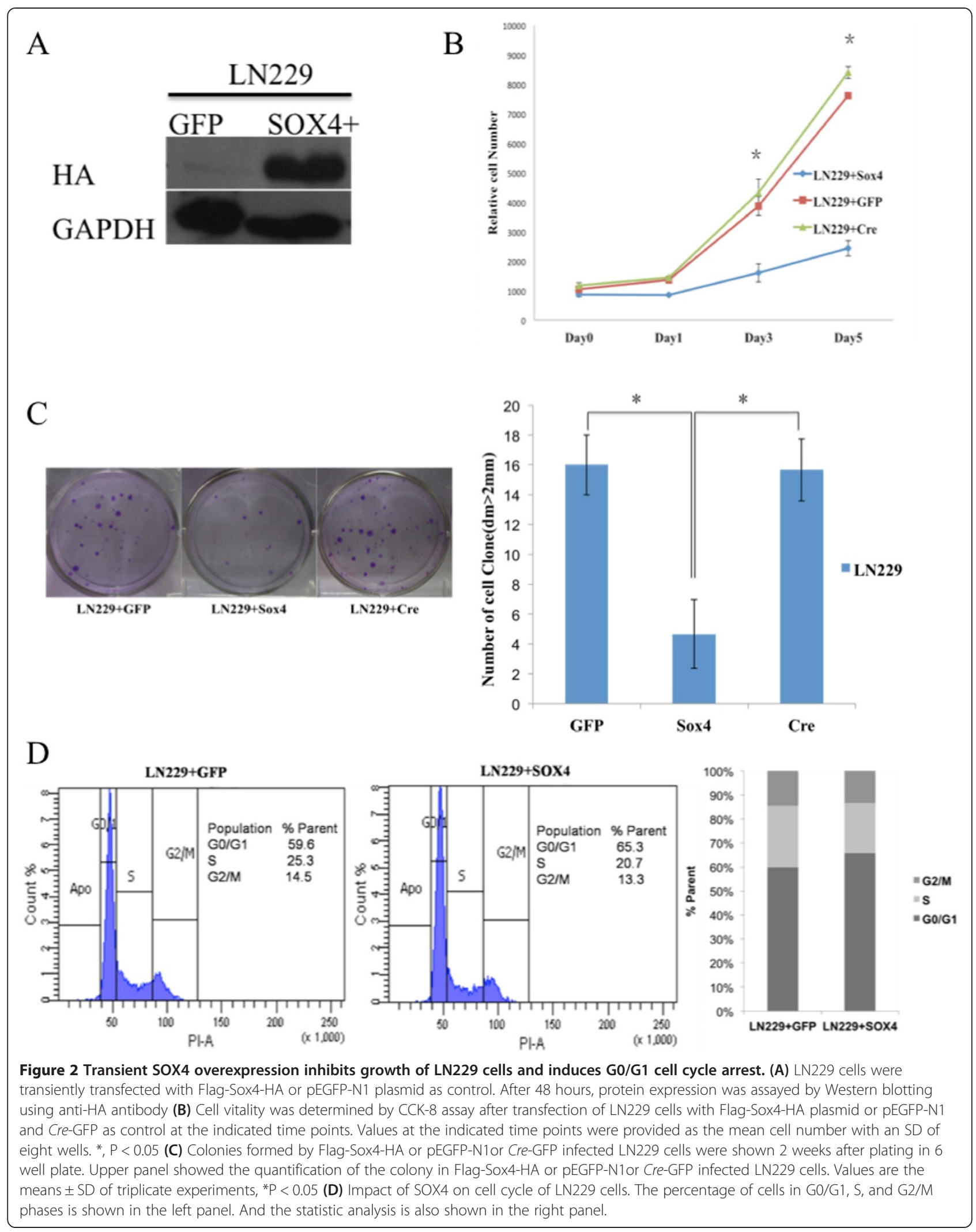




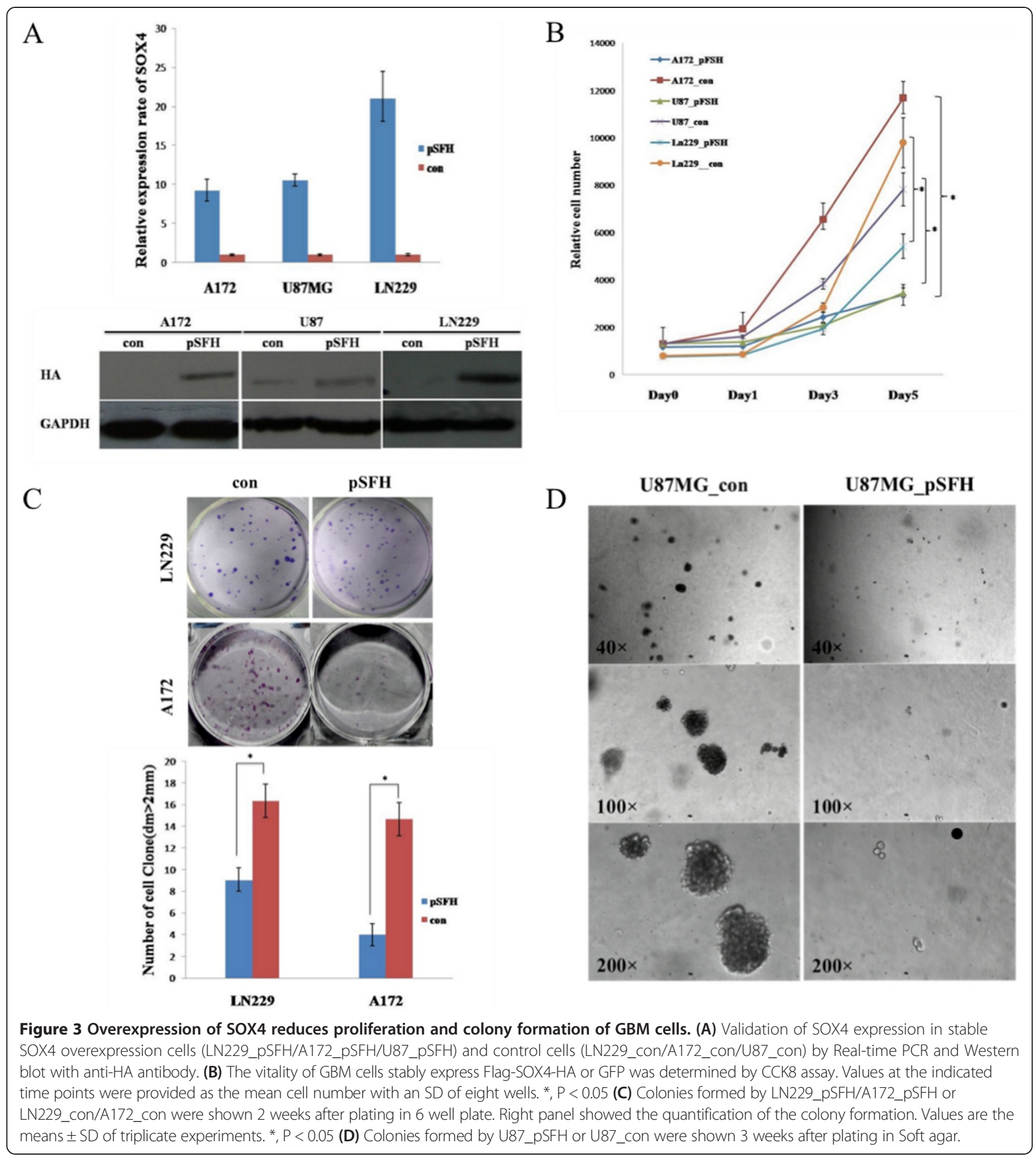

progression contains GO:0007049_cell cycle, GO:0006260_ DNA replication, GO:0006974_response to DNA damage stimulus, GO:0007017 microtubule-based process, GO:0007010 cytoskeleton organization, GO:0000075 cell cycle checkpoint with p-value $<0.001$, FDR $<0.05$ (Table 1). We also compared our list of SOX4 regulated genes in GBM cells to a previously published list of SOX4 regulated genes in prostate cancer cells [23], and we found that 54 genes are commonly changed in both glioma and prostate cancer in response to SOX4, with 33 genes upregulated and 14 genes down-regulated genes (Additional file 5: Table S3).

SOX4 was previously shown to enhance beta-catenin/ TCF activity and the proliferation of colorectal cancer cells $[29,30]$. Overexpression of SOX4 in endometrial carcinomas cell lines caused enhancement of beta-catenin/ 


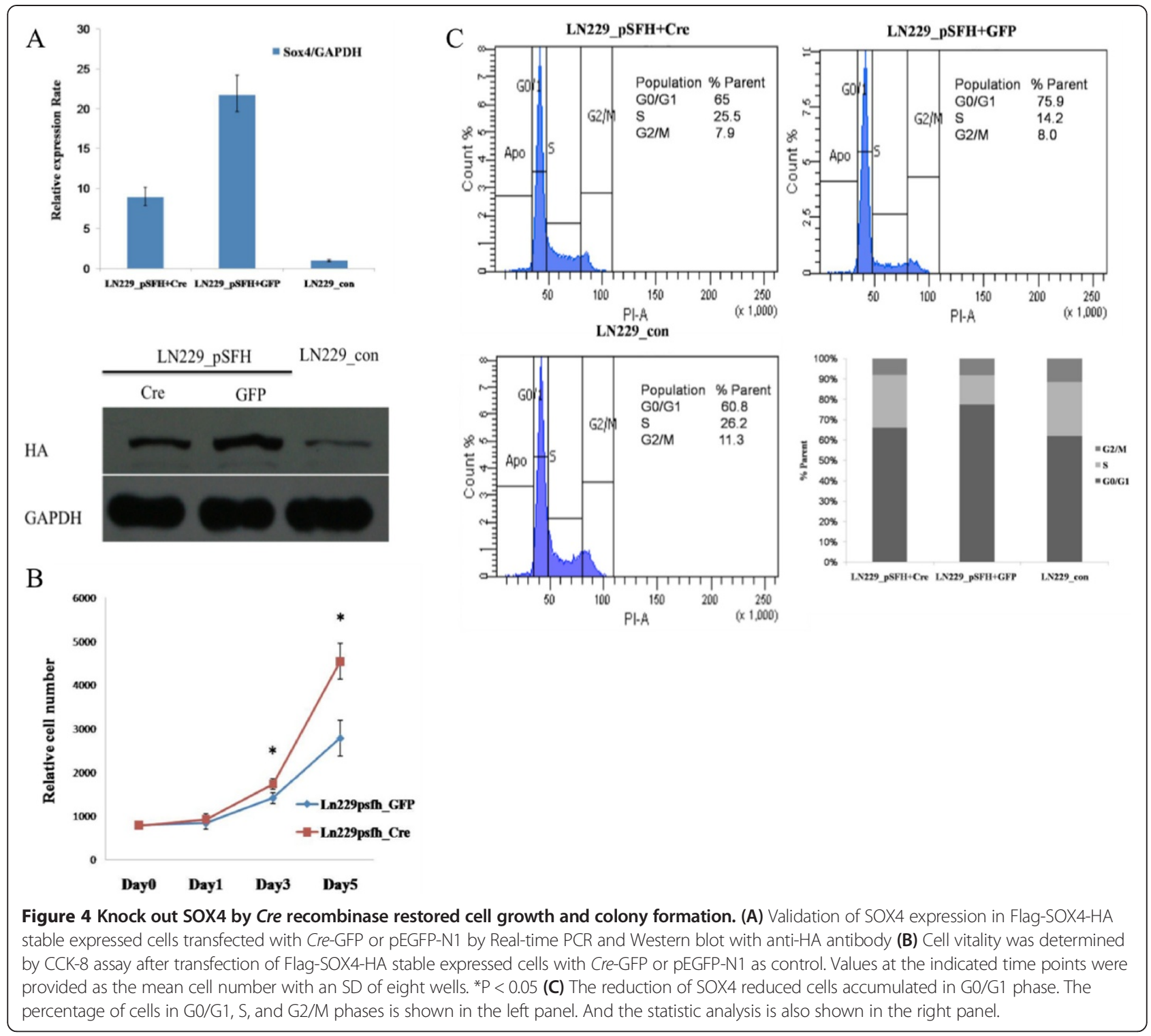

TCF4-driven transcription, whereas cells stably overexpressing SOX4 demonstrated a low proliferation rate, through transactivation of the p21 gene [31]. From our microarray data, we also found that beta-catenin is upregulated by SOX4 (Additional file 5: Table S3) in GBM cell line LN229. We further confirmed that beta-catenin is up-regulated by SOX4 by RT-PCR and western blot in all of the three GBM cell line LN229, A172 and U87 (Figure 5B). Additionally, Ser 33 and Ser 37 phosphorylation of beta-catenin by GSK3B was also increased (Figure 5C). Western blot analysis with nuclear and cytoplasmic fractions of cellular proteins indicated a strong increasment of beta-catenin in the cytoplasm but little if any changes in the nuclear after SOX4 overexpression (Figure 5D).

\section{SOX4 reduces cell proliferation and causes cell cycle} arrest via Akt-p53 axis

Previously studies have established that SOX4 interacts with and stabilizes p53 protein, a key tumor suppressor for cancers [14,32-34]. To assess whether p53 is involved in SOX4 mediated inhibition of cell proliferation and cell cycle arrest in GBM cells, we determined the expression of p53 and its downstream target p21, which is associated with growth arrest [35], by Western blot. We found that both p 21 and p53 proteins were increased by SOX4 (Figure 6A). We further showed that both SOX4 and $\mathrm{p} 53$ proteins were accumulated in the nucleus after SOX4 overexpression in GBM cells (Figure 6B).

Akt enhances Mdm2-mediated ubiquitination and degradation of p53 [36]. We therefore analyzed Akt and 


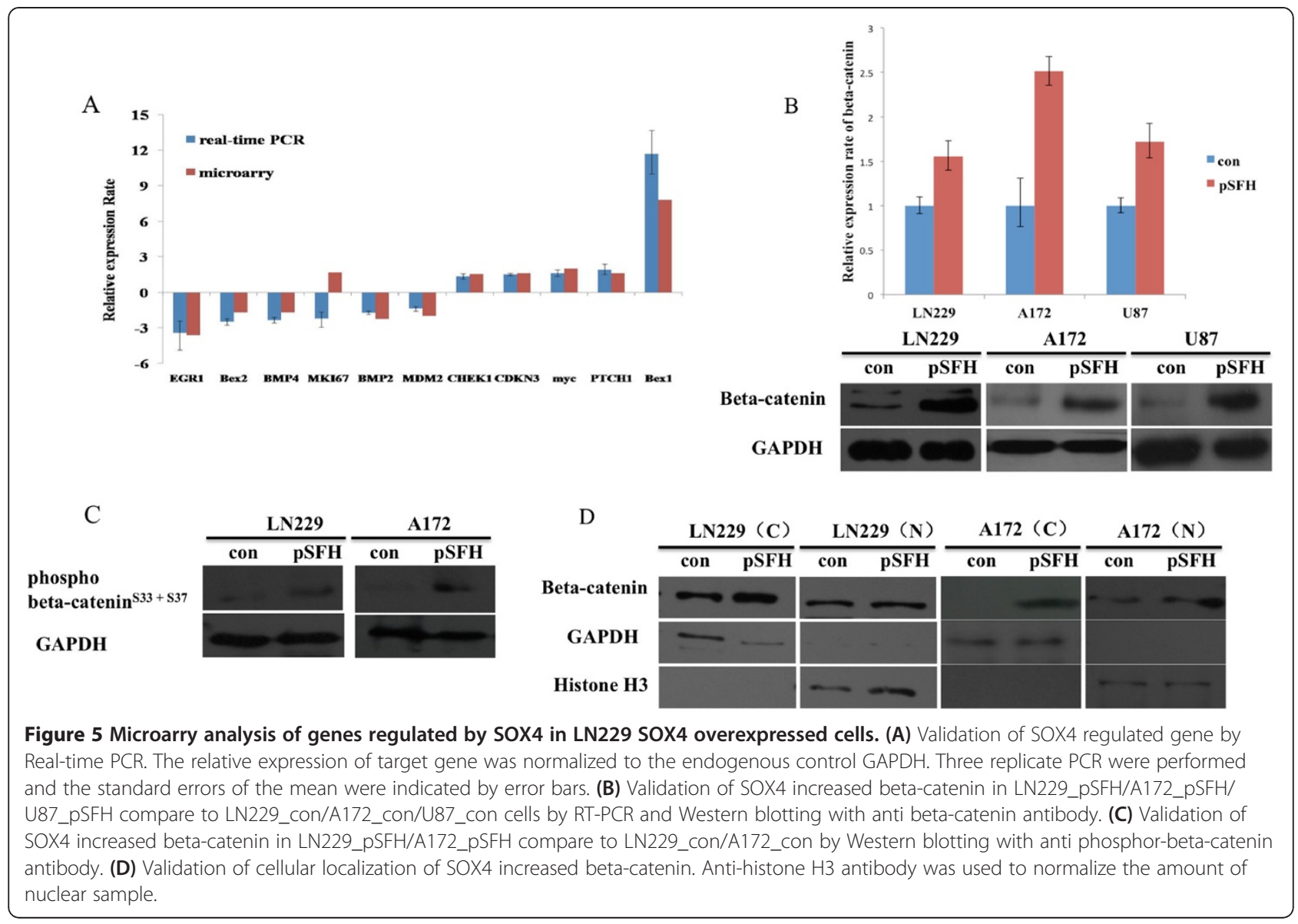

phosphorylated Akt expression after SOX4 overexpression and found that both the protein levels of AKT1 (official gene name for Akt) and phosphorylated AKT1p were down-regulated by SOX4 overexpression (Figure 6A). We showed earlier with the microarry data that MDM2, a key modulator of p53 protein levels in cells by binding to $\mathrm{p} 53$ and promotes p53 degradation via the ubiquitin/proteasome pathway, is downregulated by SOX4 in LN229 (Figure 5A). Furthermore, Ki67, a proliferation marker [37], was also found to be reduced in SOX4 overexpression GBM cells at both the mRNA (Figure 5A) and the protein levels (Figure 6A). Thus it seemed that SOX4 induced $\mathrm{p} 53$ in the nucleus is partially caused by down regulation of AKT1 and reduced phosphorylated AKT1p.

\section{Discussion}

We reported our finding that high SOX4 expression was significantly associated with good prognosis of primary GBM patients (Figure 1). However, overexpression of SOX4 in GBM cell lines inhibited cell proliferation and G0/G1 cell cycle arrest (Figures 2 and 3). These seemly contradictory observations between observation in primary clinical samples and in vitro cell line functional analysis is similar to what Aaboe et al. observed in bladder cancer [4]. They found that SOX4 is over expressed in bladder cancer tissues compared to normal tissues, but strong SOX4 expression was found to be correlated with increased patient survival $(\mathrm{P}<0.05)$ of bladder cancer patients [4], and when introduced to bladder cancer cell line HU609, it reduced cell viability by promoting apoptosis and necrosis [4]. The exact mechanism of this seemly contradict phenomena need further investigation. Sox

Table 1 Biology process enriched in SOX4 regulated gene in LN229_pSFH cells by GO analysis

\begin{tabular}{llll}
\hline GO & Annotation & Count & P Value \\
\hline GO:0007049 & Cell cycle & 187 & $8.05 \mathrm{E}-40$ \\
GO:0006260 & DNA replication & 59 & $4.30 \mathrm{E}-18$ \\
GO:0006974 & Response to DNA damage stimulus & 78 & $5.92 \mathrm{E}-13$ \\
GO:0033554 & Cellular response to stress & 96 & $3.11 \mathrm{E}-10$ \\
GO:0007010 & Cytoskeleton organization & 73 & $9.30 \mathrm{E}-08$ \\
GO:0008283 & Cell proliferation & 68 & $3.62 \mathrm{E}-06$ \\
GO:0010941 & Regulation of cell death & 100 & $4.56 \mathrm{E}-04$ \\
GO:0006916 & Anti-apoptosis & 33 & 0.001012965 \\
GO:0045596 & Negative regulation of cell & 34 & 0.001139053 \\
& differentiation & & \\
\hline
\end{tabular}




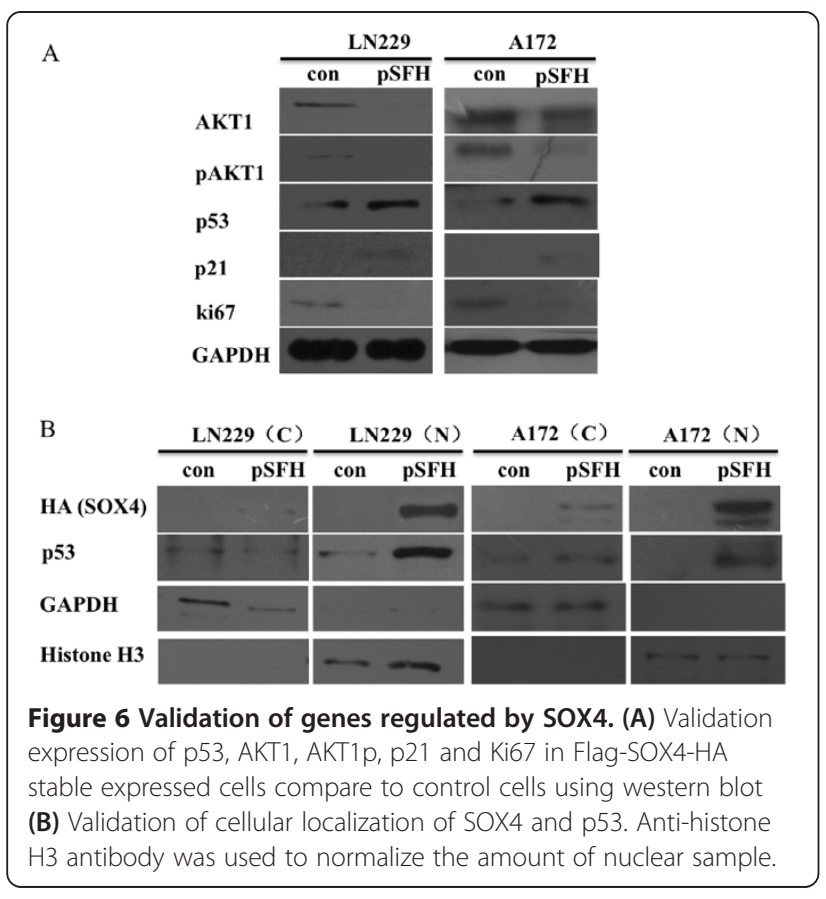

factors function as either tumor activators or repressors depending on the cellular context and associated interacting proteins [38]. One of the differences between the cell lines we used and the GMB tumor tissues is the P53 mutation status. P53 are often mutated in GBM tumors, seen in $25-30 \%$ of primary GBM and $60-70 \%$ of secondary GBM [39]. However, the GBM cell line LN229, A172 and U87 that we used in the study turned out to contain wide type p53 [40]. One possible mechanism is that SOX4 acts differently on the wild-type P53 than the mutated P53. Further experimentation is needed to verify this speculation.

The p53 protein is an important tumor suppressor that is inactivated in most tumors. It controls growth arrest and apoptosis by its transcriptional activation and repression of target genes [41]. p53 is thought to exert its function in G1 checkpoint control mainly through increased expression of the p21 gene [42]. We found p53 were increased and were accumulated in the nucleus with SOX4 (Figure 6B), while p53's downstream target p21 was up-regulated (Figure 6A), and leading to G0/G1 cell cycle arrest (Figure 4C). In addition, SOX4 reduced expression levels of AKT1 and phosphorylated AKT1 (Figure 5A), which could enhance Mdm2-mediated ubiquitination and degradation of p53 [36,43]. Thus, we propose a model to explain SOX4's action in GBM cell lines: SOX4 could down-regulate Akt, which might result in increased stability of p53, as shown by increased p53 protein expression in SOX4 overexpressed GBM cell lines and induced p21 signal which leading to G0/G1 cell cycle arrest.
SOX4 has been proposed either as an oncogenor or a tumor suppressor. Our finding that SOX4 acts as a tumor suppressor in GBM is consistent with previously reported roles of SOX4 as a tumor suppressor. For example, SOX4 induces cell apoptosis through caspase activation in hepatocarcinoma cells and HeLa cells $[14,15]$. Nuclear overexpression of SOX4 in HCC samples is correlated with diminished risk of recurrence and improved overall survival time in HCC patients [32]. Pan et al. reported that SOX4 promotes cell cycle arrest and apoptosis, and inhibits tumorigenesis by blocking Mdm2-mediated p53 degradation and facilitating $\mathrm{p} 300 / \mathrm{CBP} / \mathrm{p} 53$ complex formation [34]. In lung cancer cell line H1299, SOX4 increases PUMA expression in response to trichostatin A (TSA) and induces apoptosis in a p53 independent manner [44].

Our data proved that SOX4 inhibited cell growth and induced G0/G1 cell cycle arrest in GBM cells. We found that AKT1 and AKT1p were reduced while SOX4 overexpression in GBM and p53 protein level was increased and co-localized in nuclear with SOX4. However, SOX4 increased beta-catenin expression seems to limited to the cytoplasm and failed to initiate cytoplasm-to-nuclear translocation of beta-catenin, suggesting the action of SOX4 seems unlikely to involve directly transcriptional changes of beta-catenin directly regulated genes.

Microarray analysis showed that SOX4 regulated genes were enriched in Gene Ontology terms related to cell cycle progression (Table 1 and Additional file 5: Table S3), consistent with our functional assay showing SOX4's role in cell cycles. We also identified many interesting genes regulated by SOX4, suggesting SOX4's diverse roles in cancer cells. For example, we found SOX2 is upregulated by SOX4 (Additional file 5: Table S3), which is consistent with previous findings that the transforming growth factor- $\beta$ (TGF- $\beta$ )-Sox4-Sox 2 pathway is essential for glioma-initiating cells to retain their stemness $[18,19]$. We also identified several other genes involved in TGFbeta signaling include BMP2 and SOX10, whose expression were also changed after SOX4 overexpression (Additional file 5: Table S3).

Finally, we demonstrated that beta-catenin was upregulated by SOX4 (Figure 5B-D), suggesting a role of SOX4 in WNT signaling in GBM cells. SOX4 was previously shown to enhance beta-catenin/TCF activities in several cancer types [29-31]. p53 can reduce the proliferationsupporting effect of beta-catenin/TCF signaling by downregulating Tcf-4 expression even with transcriptional activation by beta-catenin in the nucleus [45]. Considering SOX4 increased both p53 and beta-catenin in GBM cells, there might be a cross talk between these two signals.

\section{Conclusions}

We showed that high SOX4 expression was significantly associated with good prognosis of primary GBM patients, 
suggesting the SOX4 might be a prognosis marker for GBM. However, in cell line models of GBM, SOX4 seems to behave as a tumor suppressor, a discrepancy to the good prognosis offered by the high SOX4 expression. Further investigation is necessary to understand this discrepancy and to determine the different cellular contexts in cancer cells that turn SOX4 into a tumor suppressor or tumor promoter.

\section{Additional files}

Additional file 1: Table S1. Primers used for Real-time PCR.

Additional file 2: Table S2. Clinical data of primary GBM tissues downloaded from TCGA.

Additional file 3: Figure S1. The quantitative RT-PCR results of SOX4 mRNA expression in GBM cell lines.

Additional file 4: Figure S2. Morphological change of U87 after SOX4 over expression in colony formation assay.

Additional file 5: Table S3. 633 genes regulated by SOX4 in LN229 cells and its overlap between genes regulated in LNCaP prostate cancer cells.

\section{Competing interests}

The authors declare that they have no competing interests.

\section{Authors' contributions}

BL, and JZ designed this study. JZ, HJ, RM performed the experiments. JF performed the TCGA data analysis and survival analysis. JZ, JL performed data analysis. SZ, YM, XF, NZ help to design the study and wrote the paper. All authors read and approved the final manuscript.

\section{Acknowledgements}

The work was funded by grants to BL: 81072060 from the National Natural Science Foundation of China; grants 2008DFA11320 and 2012AA022705 from the Ministry of Science and Technology, China; grant 20110101120153 from the Ministry of Education, China; grant 2012R10021 from the Zhejiang Provincial Government. The work was also funded by grants to XF: grant 2013R100262 from Qianjiang Talents Project of the Technology Office of Zhejiang Province and grant 81101580 from the National Natural Science Foundation of China. The funding agencies had no role in the study design; in the collection, analysis or interpretation of the data; in the preparation of the manuscript; or in the decision to submit the manuscript for publication. The authors declare no conflicts of interest.

\section{Author details}

${ }^{1}$ Cancer Institute (Key Laboratory of Cancer Prevention and Intervention, China National Ministry of Education), Second Affiliated Hospital, College of Medicine, Zhejiang University, Hangzhou, Zhejiang Province, P R China. ${ }^{2}$ Systems Biology Division and Propriumbio Research Center, Zhejiang-California International Nanosystems Institute (ZCNI), Zhejiang University, Hangzhou, Zhejiang Province, P R China. ${ }^{3}$ Department of Bioinformatics, School of Basic Medical Sciences, Nanjing Medical University, Nanjing, Jiangsu Province, P R China. ${ }^{4}$ Department of Urology, University of Washington, Seattle, WA 98195, USA.

Received: 26 February 2014 Accepted: 6 October 2014

Published online: 01 November 2014

\section{References}

1. Bowles J, Schepers G, Koopman P: Phylogeny of the SOX family of developmental transcription factors based on sequence and structural indicators. Dev Biol 2000, 227(2):239-255.

2. Schepers GE, Teasdale RD, Koopman P: Twenty pairs of sox: extent, homology, and nomenclature of the mouse and human sox transcription factor gene families. Dev Cell 2002, 3(2):167-170.

3. Pramoonjago P, Baras AS, Moskaluk CA: Knockdown of Sox4 expression by RNAi induces apoptosis in ACC3 cells. Oncogene 2006, 25(41):5626-5639.
4. Aaboe M, Birkenkamp-Demtroder K, Wiuf C, Sorensen FB, Thykjaer T, Sauter G, Jensen KM, Dyrskjot L, Orntoft T: SOX4 expression in bladder carcinoma: clinical aspects and in vitro functional characterization. Cancer Res 2006, 66(7):3434-3442

5. Lee S, Chen J, Zhou G, Shi RZ, Bouffard GG, Kocherginsky M, Ge X, Sun M, Jayathilaka N, Kim YC, Emmanuel N, Bohlander SK, Minden M, Kline J, Ozer O, Larson RA, LeBeau MM, Green ED, Trent J, Karrison T, Liu PP, Wang SM, Rowley JD: Gene expression profiles in acute myeloid leukemia with common translocations using SAGE. Proc Natl Acad Sci U S A 2006, 103(4):1030-1035.

6. Liu P, Ramachandran S, Ali Seyed M, Scharer CD, Laycock N, Dalton WB, Williams H, Karanam S, Datta MW, Jaye DL, Moreno CS: Sex-determining region $Y$ box 4 is a transforming oncogene in human prostate cancer cells. Cancer Res 2006, 66(8):4011-4019.

7. Huang YW, Liu JC, Deatherage DE, Luo J, Mutch DG, Goodfellow PJ, Miller DS, Huang TH: Epigenetic repression of microRNA-129-2 leads to overexpression of SOX4 oncogene in endometrial cancer. Cancer Res 2009, 69(23):9038-9046.

8. Lin B, Madan A, Yoon JG, Fang X, Yan X, Kim TK, Hwang D, Hood L, Foltz G: Massively parallel signature sequencing and bioinformatics analysis identifies up-regulation of TGFBI and SOX4 in human glioblastoma. PLoS One 2010, 5(4):e10210.

9. Rhodes DR, Yu J, Shanker K, Deshpande N, Varambally R, Ghosh D, Barrette T, Pandey A, Chinnaiyan AM: Large-scale meta-analysis of cancer microarray data identifies common transcriptional profiles of neoplastic transformation and progression. Proc Natl Acad Sci U S A 2004, 101(25):9309-9314.

10. Liao YL, Sun YM, Chau GY, Chau YP, Lai TC, Wang JL, Horng JT, Hsiao M, Tsou AP: Identification of SOX4 target genes using phylogenetic footprinting-based prediction from expression microarrays suggests that overexpression of SOX4 potentiates metastasis in hepatocellular carcinoma. Oncogene 2008, 27:5578-5589.

11. Shi Z, Qian X, Li L, Zhang J, Zhu S, Zhu J, Chen L, Zhang K, Han L, Yu S, Pu P, Jiang T, Kang C: Nuclear translocation of beta-catenin is essential for glioma cell survival. J Neuroimmune Pharmacol 2012, 7(4):892-903.

12. Judith M, De Bont JMK, Monique MCJ, Passier Roel E, Reddingius Peter AE, Sillevis S, Theo M, Luider Monique L, Den B, Rob P: Differential expression and prognostic significance of SOX genes in pediatric medulloblastoma and ependymoma identified by microarray analysis. Neuro-Oncology 2008, 10:648-660

13. Andersen $\mathrm{CL}$, Christensen LL, Thorsen $\mathrm{K}$, Schepeler T, Sorensen FB, Verspaget HW, Simon R, Kruhoffer M, Aaltonen LA, Laurberg S, Ørntoft TF: Dysregulation of the transcription factors SOX4, CBFB and SMARCC1 correlates with outcome of colorectal cancer. Br J Cancer 2009, 100(3):511-523.

14. Ahn SG, Kim HS, Jeong SW, Kim BE, Rhim H, Shim JY, Kim JW, Lee JH, Kim IK: Sox-4 is a positive regulator of Hep3B and HepG2 cells' apoptosis induced by prostaglandin (PG)A(2) and delta(12)-PGJ(2). Exp Mol Med 2002, 34(3):243-249.

15. Kim BE, Lee JH, Kim HS, Kwon OJ, Jeong SW, Kim IK: Involvement of Sox-4 in the cytochrome c-dependent AIF-independent apoptotic pathway in HeLa cells induced by Delta12-prostaglandin J2. Exp Mol Med 2004, 36(5):444-453.

16. DeAngelis LM: Brain tumors. N Engl J Med 2001, 344(2):114-123.

17. Lacroix M, Abi-Said D, Fourney DR, Gokaslan ZL, Shi W, DeMonte F, Lang FF, McCutcheon IE, Hassenbusch SJ, Holland E, Hess K, Michael C, Miller D, Sawaya R: A multivariate analysis of 416 patients with glioblastoma multiforme: prognosis, extent of resection, and survival. J Neurosurg 2001, 95(2):190-198

18. Ikushima H, Todo T, Ino Y, Takahashi M, Miyazawa K, Miyazono K: Autocrine TGF-beta signaling maintains tumorigenicity of glioma-initiating cells through Sry-related HMG-box factors. Cell Stem Cell 2009, 5(5):504-514.

19. Ikushima H, Todo T, Ino Y, Takahashi M, Saito N, Miyazawa K, Miyazono K: Glioma-initiating cells retain their tumorigenicity through integration of the sox axis and Oct4. J Biol Chem 2011, 286(48):41434-41.

20. Cerami E, Gao J, Dogrusoz U, Gross BE, Sumer SO, Aksoy BA, Jacobsen A, Byrne CJ, Heuer ML, Larsson E, Antipin Y, Reva B, Goldberg AP, Sander C, Schultz N: The cBio cancer genomics portal: an open platform for exploring multidimensional cancer genomics data. Cancer Discov 2012, 2(5):401-404.

21. Gao J, Aksoy BA, Dogrusoz U, Dresdner G, Gross B, Sumer SO, Sun Y, Jacobsen A, Sinha R, Larsson E, Cerami E, Sander C, Schultz N: Integrative 
analysis of complex cancer genomics and clinical profiles using the cBioPortal. Sci Signal 2013, 6(269):11.

22. Therneau TM: A package for survival analysis in S. 2014, R package version 2.37-7. http://CRAN.R-project.org/package=survival.

23. Scharer CD, McCabe CD, Ali-Seyed M, Berger MF, Bulyk ML, Moreno CS: Genome-wide promoter analysis of the SOX4 transcriptional network in prostate cancer cells. Cancer Res 2009, 69(2):709-717.

24. Bunting M, Bernstein KE, Greer JM, Capecchi MR, Thomas KR: Targeting genes for self-excision in the germ line. Genes Dev 1999, 13(12):1524-1528.

25. Livak KJ, Schmittgen TD: Analysis of relative gene expression data using real-time quantitative PCR and the 2(-Delta Delta C(T)) Method. Methods 2001, 25(4):402-408.

26. da Huang W, Sherman BT, Lempicki RA: Systematic and integrative analysis of large gene lists using DAVID bioinformatics resources. Nat Protoc 2009, 4(1):44-57.

27. Huang DAW, Sherman BT, Tan Q, Kir J, Liu D, Bryant D, Guo Y, Stephens R, Baseler MW, Lane HC, Lempicki RA: DAVID Bioinformatics resources: expanded annotation database and novel algorithms to better extract biology from large gene lists. Nucleic Acids Res 2007, 35(Web Server issue): W169-W175.

28. Hur EH, Hur W, Choi JY, Kim IK, Kim HY, Yoon SK, Rhim H: Functional identification of the pro-apoptotic effector domain in human Sox4. Biochem Biophys Res Commun 2004, 325(1):59-67.

29. Lee AK, Ahn SG, Yoon JH, Kim SA: Sox4 stimulates ss-catenin activity through induction of CK2. Oncol Rep 2011, 25(2):559-565.

30. Sinner D, Kordich JJ, Spence JR, Opoka R, Rankin S, Lin SC, Jonatan D, Zorn AM, Wells JM: Sox17 and Sox4 differentially regulate beta-catenin/ T-cell factor activity and proliferation of colon carcinoma cells. Mol Cell Biol 2007, 27(22):7802-7815

31. Saegusa M, Hashimura M, Kuwata T: Sox4 functions as a positive regulator of beta-catenin signaling through upregulation of TCF4 during morular differentiation of endometrial carcinomas. Lab Investig J Tech Meth Pathol 2012, 92(4):511-521.

32. Hur W, Rhim H, Jung CK, Kim JD, Bae SH, Jang JW, Yang JM, Oh ST, Kim DG, Wang HJ, Lee SB, Yoon SK: SOX4 overexpression regulates the p53mediated apoptosis in hepatocellular carcinoma: clinical implication and functional analysis in vitro. Carcinogenesis 2010, 31(7):1298-1307.

33. Pan $\mathrm{S}$, Cheng L, White JT, Lu W, Utleg AG, Yan X, Urban ND, Drescher CW, Hood L, Lin B: Quantitative proteomics analysis integrated with microarray data reveals that extracellular matrix proteins, catenins, and p53 binding protein 1 are important for chemotherapy response in ovarian cancers. OMICS 2009, 13(4):345-354.

34. Pan X, Zhao J, Zhang WN, Li HY, Mu R, Zhou T, Zhang HY, Gong WL, Yu M, Man JH, Zhang PJ, Li AL, Zhang XM: Induction of SOX4 by DNA damage is critical for p53 stabilization and function. Proc Natl Acad Sci U S A 2009, 106(10):3788-3793.

35. Tang HY, Zhao K, Pizzolato JF, Fonarev M, Langer JC, Manfredi JJ: Constitutive expression of the cyclin-dependent kinase inhibitor p21 is transcriptionally regulated by the tumor suppressor protein $\mathrm{p} 53$. J Biol Chem 1998, 273(44):29156-29163.

36. Ogawara Y, Kishishita S, Obata T, Isazawa Y, Suzuki T, Tanaka K, Masuyama $\mathrm{N}$, Gotoh Y: Akt enhances Mdm2-mediated ubiquitination and degradation of p53. J Biol Chem 2002, 277(24):21843-21850.

37. Scholzen T, Gerdes J: The Ki-67 protein: from the known and the unknown. J Cell Physiol 2000, 182(3):311-322.

38. Sarkar $A$, Hochedlinger $K$ : The sox family of transcription factors: versatile regulators of stem and progenitor cell fate. Cell Stem Cell 2013, 12(1):15-30.

39. England B, Huang T, Karsy M: Current understanding of the role and targeting of tumor suppressor p53 in glioblastoma multiforme. Tumour Biol 2013, 34(4):2063-2074

40. Van Meir EG, Kikuchi T, Tada M, Li H, Diserens AC, Wojcik BE, Huang HJ, Friedmann T, de Tribolet N, Cavenee WK: Analysis of the p53 gene and its expression in human glioblastoma cells. Cancer Res 1994, 54(3):649-652.

41. Vousden KH, Lu X: Live or let die: the cell's response to p53. Nat Rev Cancer 2002, 2(8):594-604.

42. Deng C, Zhang P, Harper JW, Elledge SJ, Leder P: Mice lacking p21CIP1/ WAF1 undergo normal development, but are defective in $\mathrm{G} 1$ checkpoint control. Cell 1995, 82(4):675-684.

43. Wade M, Li YC, Wahl GM: MDM2, MDMX and p53 in oncogenesis and cancer therapy. Nat Rev Cancer 2013, 13(2):83-96.
44. Jang SM, Kang EJ, Kim JW, Kim CH, An JH, Choi KH: Transcription factor Sox4 is required for PUMA-mediated apoptosis induced by histone deacetylase inhibitor, TSA. Biochem Biophys Res Commun 2013, 438(2):445-451.

45. Rother K, Johne C, Spiesbach K, Haugwitz U, Tschop K, Wasner M, Klein-Hitpass L, Moroy T, Mossner J, Engeland K: Identification of Tcf-4 as a transcriptional target of p53 signalling. Oncogene 2004, 23(19):3376-3384.

doi:10.1186/s12883-014-0207-y

Cite this article as: Zhang et al: SOX4 inhibits GBM cell growth and induces G0/G1 cell cycle arrest through Akt-p53 axis. BMC Neurology 2014 14:207.

\section{Submit your next manuscript to BioMed Central and take full advantage of:}

- Convenient online submission

- Thorough peer review

- No space constraints or color figure charges

- Immediate publication on acceptance

- Inclusion in PubMed, CAS, Scopus and Google Scholar

- Research which is freely available for redistribution 